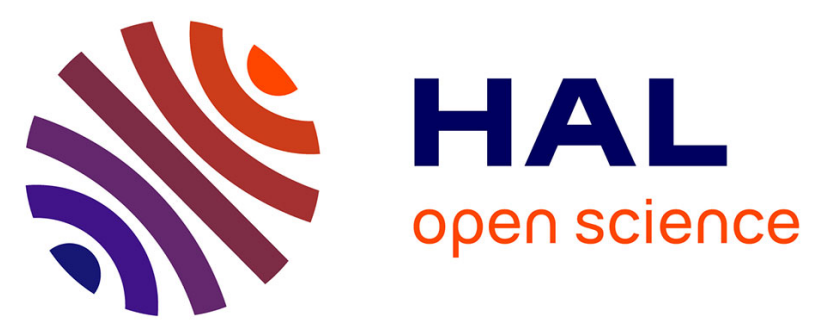

\title{
Genetic disruption of calpain correlates with loss of membrane blebbing and differential expression of RhoGDI-1, cofilin and tropomyosin
}

Anna K Larsen, René Lametsch, John S Elce, Jørgen K Larsen, Bo Thomsen, Martin R Larsen, Moira A Lawson, Peter A Greer, Per Ertbjerg

\section{To cite this version:}

Anna K Larsen, René Lametsch, John S Elce, Jørgen K Larsen, Bo Thomsen, et al.. Genetic disruption of calpain correlates with loss of membrane blebbing and differential expression of RhoGDI-1, cofilin and tropomyosin. Biochemical Journal, 2008, 411 (3), pp.657-666. 10.1042/BJ20070522 . hal00478787

\section{HAL Id: hal-00478787 \\ https://hal.science/hal-00478787}

Submitted on 30 Apr 2010

HAL is a multi-disciplinary open access archive for the deposit and dissemination of scientific research documents, whether they are published or not. The documents may come from teaching and research institutions in France or abroad, or from public or private research centers.
L'archive ouverte pluridisciplinaire HAL, est destinée au dépôt et à la diffusion de documents scientifiques de niveau recherche, publiés ou non, émanant des établissements d'enseignement et de recherche français ou étrangers, des laboratoires publics ou privés. 


\title{
Genetic disruption of calpain correlates with loss of membrane blebbing and differential expression of RhoGDI-1, cofilin and tropomyosin
}

\author{
Anna K. Larsen*, René Lametsch*, John S. Elce†, Jørgen K. Larsen†, Bo Thomsen§, \\ Martin R. Larsen||, Moira A. Lawson*, Peter A. Greer $₫$ and Per Ertbjerg*. \\ * Department of Food Science, Faculty of Life Sciences, University of Copenhagen, Denmark \\ † Department of Biochemistry, Queen's University, Kingston, Ontario, Canada \\ $\ddagger$ Finsen Laboratory, Finsen Center, Rigshospitalet, Copenhagen, Denmark \\ $\S$ Dept. of Genetics and Biotechnology, Faculty of Agricultural Science, University of Aarhus, Denmark \\ || Department of Biochemistry and Molecular Biology, University of Southern Denmark, Denmark \\ ฯ Queen's Cancer Research Institute, Queen's University, Kingston, Ontario, Canada
}

\section{Corresponding author:}

Anna Karina Larsen, Dept. of Food Science,

Faculty of Life Sciences, University of Copenhagen

Rolighedsvej 30, DK-1958 Frederiksberg C, Denmark,

Phone: +4535333184

Fax: +4535333341

e-mail: akl@life.ku.dk

Page heading: Calpain is required for membrane blebbing

Keywords: m-calpain, GFP, proteomics, RhoGDI-1, cofilin, tropomyosin 


\section{List of complete address affiliations:}

* Anna K. Larsen, René Lametsch, Moira A. Lawson and Per Ertbjerg:

Department of Food Science, Faculty of Life Sciences, University of Copenhagen,

Rolighedsvej 30, DK-1958 Frederiksberg C, Denmark.

rla@life.ku.dk, mal@,life.ku.dk and

peer@life.ku.dk Tel: + 4535333255

† John S. Elce:

Department of Biochemistry, Queen's University,

Botterell Hall, Kingston, Ontario, Canada K7L 3N6,

jse@post.queensu.ca

$\ddagger$ Jørgen K. Larsen:

Finsen Laboratory \& Experimental Pathology Unit, Rigshospitalet, Copenhagen Biocenter,

Ole Maaløes Vej 5, DK-2200 København N, Denmark.

j.k.larsen@finsenlab.dk

Tel: +4535456082

$\S$ Bo Thomsen:

Dept. of Genetics and Biotechnology, Faculty of Agricultural Sciences, University of Aarhus, Research Centre Foulum, Blichers Allé 20, DK-8830 Tjele.

Bo.Thomsen@agrisci.dk

Tel: +4589991900

|| Martin R. Larsen:

Department of Biochemistry and Molecular Biology, University of Southern Denmark, DK-5230 Odense, Denmark.

mrl@bmb.sdu.dk

Tel: +45655023 42

I| Peter A. Greer:

Queen's University Cancer Research Institute, Botterell Hall, Room A309,

Kingston, Ontario K7L 3N6, Canada.

greerp@post.queensu.ca

Tel: (613) 5332813 


\section{ABBREVIATIONS}

FACS: fluorescence-activated cell sorting

FAK: focal adhesion kinase

FN: fibronectin

GFP: green fluorescent protein

LIMK: Lin11, Is11, Mec3 kinases

MALDI-TOF-MS: Matrix-assisted laser desorption/ionization time-of-flight mass spectrometry

MARCKS: myristylated alanine-rich $\mathrm{C}$ kinase substrate

MEF: mouse embryonic fibroblast

MLC: myosin light chain

MLCK: myosin light chain kinase

MLCP: myosin light chain phosphatase

PAK: p21-activated kinase

PKC: protein kinase $\mathrm{C}$

RhoGDI: Rho GDP-dissociation inhibitor

ROCK: Rho-associated kinase

Tm2: Tropomyosin $1(\alpha)$, splice isoform 2 


\section{SYNOPSIS}

Dynamic regulation of the actin-cytoskeleton is essential to cell motility, spreading, and the formation of membrane surface extensions like lamellipodia, ruffles and blebs. The ubiquitous calpains contribute to integrin-mediated cytoskeletal remodelling during cell migration and spreading, by cleavage of focal adhesion components and signalling molecules. In this study, the live-cell morphology of calpain-knockout and wild type cells was examined by time-lapse fluorescence microscopy and a role of calpain in mediating formation of sporadic membrane blebs was established. Membrane blebbing was significantly reduced in calpain-knockout cells, and genetic rescue fully restored the wild type phenotype in knockout cells. Proteomic comparison of wild type and knockout cells identified decreased levels of RhoGDI-1 and cofilin 1 , and increased levels of tropomyosin in calpain knockout cells, suggesting a role of calpain in regulating membrane extensions involving these proteins. RhoGDI, cofilin and tropomyosin are known regulators of actin filament dymamics and membrane extensions. The reduced levels of RhoGDI-1 in calpain-knockout cells observed by proteome analysis were confirmed by immunoblotting. Genetic rescue of the calpainknockout cells enhanced RhoGDI-1-expression 2-fold above that normally present in wild type cells. These data suggest a regulatory connection between calpain and RhoGDI-1 to promote formation of membrane blebs.

(197 words) 


\section{INTRODUCTION}

Active remodelling of the cytoskeleton is fundamental to most biological processes that involve motility and changes in cell morphology, including cell migration, spreading, division and cell fusion. Through their interactions with components of signalling pathways, focal adhesions and the cytoskeleton, the ubiquitous calpains are regulators of such changes [1-3].

A range of cell surface protrusions, including lamellipodia, pseudopodia, filopodia, membrane ruffles and blebs are integral phenomena of eukaryotic cell motility, that rely on the dynamic reorganization of the actin cytoskeleton, mediated by small GTPases of the Rho family [4]. Rho, Rac and Cdc 42 proteins are essential regulators of diverse aspects of cell morphology and motility. They are tightly regulated at several levels, including by the Rho GDP-dissociation inhibitors (RhoGDIs) [5]. The precise functional significance of blebs, ruffles and lamellipodia, and the mechanisms leading to their formation are not fully understood; but these phenomena all appear to relate to cell migration [6;7]. Membrane blebs are hyaline, typically spherical cell-surface extensions that occur during apoptosis [8;9], cell division [10] and migration [11]. Blebs are very transient and dynamic in nature, and may transform into, or alternate with other extensions like ruffles and lamellipodia [11]. Lamellipodia and ruffles are flat F-actin dense extensions that normally protrude along the leading edge of migrating cells [4][12]. Membrane blebbing was initially associated with apoptosis [8;9] and cell injury [13;14] and a retracted, round cell morphology associated with large, highly dynamic membrane blebs are indeed key features of apoptosis. Non-apoptotic blebs that evolve during cell division and migration are less studied, but have been reported to differ from apoptotic blebs with regards to size, shape and F-actin distribution [9]. Blebbing reflects a general loss of adhesion strength between the actin cytoskeleton and the plasma membrane [15] and is initiated by membrane detachment from the underlying actin layer. Bleb expansion is a passive process, driven by a flow of fluid; and is independent on actin polymerization, unlike ruffles or lamellipodia. Bleb retraction, however requires actin filament assembly, myosin II-dependent contraction [16] and is controlled by the phosphorylation of myosin II regulatory light chain (MLC) [8]. MLC phosphorylation is regulated by myosin light chain kinase (MLCK), myosin light chain phosphatase (MLCP), the downstream Rho effector, ROCK (Rho-associated kinase) and PAK (p21-activated kinase) [17]. Activation of ROCK appears to be crucial for bleb formation, and may involve interaction with activated Rho, or occur by constitutive activation via caspase-3-mediated cleavage of its auto-inhibitory domain [18;19]. Another ROCK-substrate involved in formation of blebs, ruffles and cell migration includes the LIMKs (Lin11, Isl1 and Mec3 kinases). The phosphorylation of LIMK by ROCK or PAKs in turn increases LIMK-mediated phosphorylation of cofilin, which changes its F-actin modulating activity, and facilitates actin cytoskeleton dynamics [20]. Cofilin is essential for the rapid turnover of actin filaments, actin polymerization, and membrane protrusions, and has the capacity to determine the direction of cell motility [21;22].

Calpains are intracellular $\mathrm{Ca}^{2+}$-dependent cysteine proteases involved in various cellular functions. A range of structural and signalling proteins implicated in cytoskeletal remodelling, are cleaved by the ubiquitous $\mu$ - and m-calpains, including spectrin, talin, paxillin, focal adhesion kinase (FAK) and $\beta 3$-integrin 
[3;23-25]. Calpains have also been reported to directly modulate PKC [26], Rho A [27], and some proteins involved in bleb formation, including several ROCK substrates [17] and MLCK, in vitro [28]. The ubiquitous $\mu$ - and m-calpains are heterodimers composed of distinct $80 \mathrm{kDa}$ catalytic subunits (encoded by capn1 and capn2, respectively) and a common $28 \mathrm{kDa}$ regulatory subunit (encoded by capn4). Both subunits undergo autolysis from their N-termini, as part of the activation/degradation mechanism, and plasma membrane translocation is associated with $\mu$-calpain activation in platelets and erythrocytes upon treatment with the $\mathrm{Ca}^{2+}$-ionophores ionomycin and A23187 [29;30]. Localization of m-calpain has been inyestigated in several cell types, but its membrane localization has not been resolved [23].

The physiological functions of $\mu$ - and m-calpain have been addressed by gene knockout studies in mice [31-34]. Homozygous deletion of the capn4 gene abolished both $\mu$-and $\mathrm{m}$-calpain activities, resulting in embryonic lethality [31][34][35]. Disruption of capn2 also resulted in pre-implantation embryonic lethality [33]. In contrast, disruption of capn1, which eliminated only $\mu$-calpain, resulted in viable and fertile mice with a platelet aggregation defect [32]. Collectively these studies provide compelling genetic evidence for an essential role for m-calpain in mammalian development. Mouse embryonic fibroblasts derived from capn4 knockout mice (capn4 ${ }^{-/-}$MEFs) represent powerful genetic model systems to study the physiological functions of calpain [3;31]. The objective of the present study was to address the biological significance of calpain with regard to cell morphology and motility. The capn4 MEFs were used to explore the role of calpain in these phenomena [3;31]. Time-lapse fluorescence microscopy of cells cultured on un-coated glasssurfaces revealed that the occurrence of sporadic, apparently non-apoptotic membrane blebs observed in wild type MEFs, was significantly reduced in capn 4 knockout relative to the wild type cells. Co-transfection of capn $^{-/-}$MEFs with a plasmid encoding the $28 \mathrm{kDa}$ small subunit and a GFP-tagged m-calpain $80 \mathrm{kDa}$ subunit (m80k-GFP) completely restored the blebbing behaviour, suggesting that calpain has a critical role in sporadic membrane blebbing. Proteomic comparison of wild type and capn ${ }^{-/-}$MEFs revealed significant differences in the levels of RhoGDI-1, cofilin 1 and fibroblast tropomyosin isoform (Tm2). A connection between RhoGDI-1 and calpain expression was further established by immunoblotting analysis of wild type, capn $^{-/ 2}$ MEFs and genetically rescued capn $4^{-/-}$MEFs. Our data thus point to a calpain-dependent and possibly RhoGDI-1-mediated mechanism contributing to formation of membrane blebs.

\section{EXPERIMENTAL}

\section{Plasmids, constructs and primers}

The m80k-pEGFP expression vector, encoding a GFP-tagged $80 \mathrm{kDa}$ subunit of rat m-calpain (m80kGFP), was constructed by PCR amplification of the full length capn2 sequence from rat-m80k-CHis6-pET24 [36]. DNA was amplified for 30 cycles, using Vent ${ }^{\circledR}$ DNA Polymerase. Primer sequences were 5'-GTT TAG CTA GCA GAA GGA GAT ATA CCA TG-3' for the forward and 5'-GCG GCC GCA AGC TTA CCT AG-3' for the reverse primer, with restriction sites for NheI and HindIII endonucleases underlined in the primers. The PCR amplified product was digested with NheI and HindIII, purified and ligated into pEGFP-N1 (Clontech Laboratories, Inc.) encoding enhanced GFP (EGFP). All enzymes were from New 
England Biolabs, Inc. The boundaries of the resulting m80k-EGFP fusion protein were as follows: (m80k)WLSFSVL-GKLRILQSTVPRARDPPVAT-MVSKGEE-(EGFP) where the letters in italics represent linker peptide and letters in bold indicate the C- and N-termini of $80 \mathrm{kDa}$ m-calpain and EGFP, respectively. The expression vector rat-28k-pMSCV, similar to rat-28k-pSBC [3] encoding the $28 \mathrm{kDa}$ subunit was obtained by subcloning of the $28 \mathrm{k}$ cDNA sequence from rat-28k-pCR ${ }^{\circledR} 2.1$ (J. S. Elce, unpublished) into pMSCVpuroNotI-linker. A SalI-EcoRI fragment of rat-28k-pCR ${ }^{\circledR} 2.1$ was ligated into the XhoI and EcoRI-sites of pMSCVpuro by means of XhoI- and EcoRI-digestion. Correctly cloned plasmids were identified by restriction analysis followed by automated DNA sequencing by MWG Biotech AG, Ebersberg, Germany and Cortec DNA Service Laboratories, Inc., Canada.

\section{Cell culture and transfection}

The capn $4^{-/}$and wild type mouse embryonic fibroblast (MEF) cell lines used in this study were established by SV40 large T-antigen immortalization of the corresponding primary cells [3;31]. Cells were maintained in Dulbecco's Modified Eagles Medium, DMEM (Sigma) supplemented with 10\% Fetal calf serum (Invitrogen), $100 \mathrm{U} / \mathrm{mL}$ penicillin and $100 \mu \mathrm{g} / \mathrm{mL}$ streptomycin (Invitrogen), at $37^{\circ} \mathrm{C}$ and $5 \% \mathrm{CO}_{2}$ in a humid atmosphere.

Transient transfections with the various vector constructs were performed in $35 \mathrm{~mm}$ or $100 \mathrm{~mm}$ dishes using the PolyFect ${ }^{\circledR}$ Transfection Reagent (Qiagen) according to the manufacturer's instructions. To increase the probability of achieving co-transfection with the two types of plasmid, a 1.5 fold mass excess of the plasmid encoding the small subunit was used relative to that encoding m80k-GFP. Transfections for

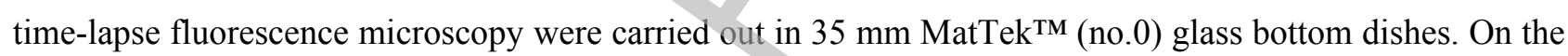
day before transfection $10^{5}$ cells per well were seeded in $3 \mathrm{~mL}$ of culture medium. On the day of transfection, $1.5 \mu \mathrm{g}$ m80k-pEGFP and $2.25 \mu \mathrm{g}$ pSBC-28k (or 28k-pMSCV) DNA were mixed with $10 \mu \mathrm{L}$ PolyFect Reagent diluted to $100 \mu \mathrm{L}$ final in serum free DMEM and added to the cells. Control cells were transfected with $3.75 \mu \mathrm{g}$ pEGFP-N1. Cell cultures were incubated for 24 hours to allow GFP expression. Transfection in $100 \mathrm{~mm}$ dishes was briefly as follows: $1.6 \times 10^{6}$ cells were seeded in $8 \mathrm{~mL}$ of culture medium. Transfection was with $4 \mu \mathrm{g}$ m80k-pEGFP and $6 \mu \mathrm{g}$ pSBC-28k plasmid DNA mixed with $25 \mu \mathrm{L}$ PolyFect Reagent in 300 $\mu \mathrm{L}$ (final) serum free DMEM which was added to the cells. Cells subjected to FACS cell sorting were transfected in $100 \mathrm{~mm}$ dish format as described above. Cells with high m80k-GFP expression (m-calpainGFP) were separated from non-transfected and low expressing cells using a BD FACS Vantage SE Diva cell sorter with the following settings; $100 \mu \mathrm{m}$ flow nozzle, Diva option and purity mode sorting.

\section{Epifluorescence microscopy}

For fluorescence microscopy, cells were transfected either in $35 \mathrm{~mm}$ MatTek ${ }^{\mathrm{TM}}$ glass bottom culture dishes for live cell studies, or on $24 \times 24 \mathrm{~mm}$ glass cover slips (no.1) in 6-well dishes (35 mm) for fixed samples. Cells grown on cover slips were washed twice with PBS and fixed with 4\% paraformaldehyde in PBS for 10 minutes at RT. After fixation, the cells were washed with PBS, incubated with TRITC-phalloidin (Sigma) 
diluted in PBS, washed and mounted on microscope object glasses using DAKO ${ }^{\circledR}$ Fluorescent mounting medium (DAKO A/S, Denmark). Time-lapse recordings of live cells were carried out in $2 \mathrm{~mL}$ of growth medium, which was replaced at least 2 hours prior to the experiment. $35 \mathrm{~mm}$ MatTek glass bottom dishes were placed on a $37^{\circ} \mathrm{C}$ heated stage (Tempcontrol 37-2 digital by PeCon; Leica, Germany) on an inverted microscope. The microscope (Leica DM IRB) was equipped with an infinity corrected PL FLUOTAR 63x /0.70 objective and a manual shutter. Green fluorescence was recorded with a FITC filter (Leica). Images were recorded with an Evolution QE Monochrome CCD camera (Media Cybernetics Inc.) and image recording was controlled by the ImagePro®Plus (version 4.5.1) software package (Media Cybernetics Inc., USA). Time-lapse series of 20 images per microscopic field were recorded over 400 to 600 seconds in 20-30 second intervals and variable exposure times, shutting off the light in between each exposure. Images were sequentially observed to visualize cellular movements within the given time frame. Recordings of $\mathrm{Ca}^{2+}$ ionophore stimulated cells were carried out similarly, beginning with $\mathrm{t}=0$ at the addition of $5 \mu \mathrm{M} \mathrm{A} 23187$ to the medium.

\section{Immunoblotting and antibodies}

For immunoblotting, cells were harvested, washed with ice-cold PBS and centrifuged at $1000 \mathrm{~g}$ for 5 minutes at $4^{\circ} \mathrm{C}$. The recovered fibroblasts were resuspended in lysis buffer (50 mM HEPES, pH 7.6, $150 \mathrm{mM}$ $\mathrm{NaCl}, 1 \%$ Triton X-100, $5 \mathrm{mM}$ EDTA, $10 \mathrm{mM}$ 2-mercaptoethanol, $0.1 \mathrm{mM}$ PMSF, $10 \mu \mathrm{g} / \mathrm{mL}$ leupeptin), incubated on ice for 5 minutes and centrifuged at $10000 \mathrm{x}$ g for 10 minutes at $4^{\circ} \mathrm{C}$. Protein concentration was determined using the bicinchoninic acid (BCA) protein assay kit (Pierce, Chemical Company, Rockford, USA). Protein samples of the soluble cell lysates were denatured with SDS sample buffer, resolved on 9\% Tris-Tricine SDS-PAGE gels followed by transfer at $30 \mathrm{~V}$ in Tris glycine transfer buffer $(20 \%$ methanol, $88.8 \mathrm{mM}$ glycine, $25 \mathrm{mM}$ Tris- $\mathrm{HCl} \mathrm{pH} 8.3$ ) or using 4-12\% Bis-Tris NuPAGE pre-cast gels (with MES running buffer) and NuPAGE transfer buffer for blotting onto $(0.2 \mu \mathrm{m})$ PVDF membranes (Invitrogen). Membranes were blocked in $10 \mathrm{mM}$ Tris- $\mathrm{HCl}$ pH 8.0, $150 \mathrm{mM} \mathrm{NaCl}, 0.12 \%$ Tween-20 (TBST) with 5\% low fat dry milk and incubated for 1 hour at RT with primary antibodies appropriately diluted in TBST with $1 \%$ milk. Antibodies used for detection were rabbit anti-human m80k N-terminal peptide antibody (RP2) (Triple Point Biologics, Inc. 1:10000), rabbit anti-GFP/EGFP Living Colors ${ }^{\circledR}$ Peptide Antibody (\#8367-1) (Clontech Laboratories, Inc. 1:200), a polyclonal rabbit antibody against rat m-calpain (80k/21k) [37] and rabbit anti-RhoGDI (\#A20, Santa Cruz Biotechnology, 1:5000). After incubation, membranes were repeatedly washed in large volumes of TBST. Secondary antibodies were HRP-conjugated anti-rabbit IgG antibody (\#W4011, Promega Biosciences, Inc. and NA934V, Amersham Pharmacia Biotech) diluted 1:5000 in TBST 5\% milk. After this incubation, membranes were thoroughly washed and the immunoblots were developed using enhanced chemiluminescence kits (ECL+ from Amersham Pharmacia Biotech or Renaissance, NEN Life Science Products). 


\section{Two-dimensional electrophoresis and protein identification}

Cells were expanded in growth medium until $80-90 \%$ confluence. Before harvest, the cells were washed twice with PBS and then scraped and pooled into ice-cold PBS. The cells were then centrifuged $1000 \mathrm{~g}$ for $5 \mathrm{~min}$ at $4^{\circ} \mathrm{C}$, resuspended in ice-cold lysis buffer (50 mM HEPES, pH 7.5, $5 \mathrm{mM}$ EDTA, 1\% Triton X-100, 2 mM DTT) followed by brief sonication (8-10 bursts of $\leq 1$ second each) and centrifugation at $20000 \mathrm{~g}$ for 15 minutes at $4^{\circ} \mathrm{C}$. The supernatants, containing the soluble cytosolic fraction, were divided into aliquots and used for protein determination or mixed with glycerol to $50 \%$, for storage at $-80^{\circ} \mathrm{C}$ until use. Protein concentration was determined with the BCA assay (Pierce). Two-dimensional gel electrophoresis was performed using the Criterion pre-cast gel system from Bio-Rad using $40 \mu \mathrm{g}$ protein samples for analytical gels, and $75 \mu \mathrm{g}$ samples for preparative gels. Samples diluted into $200 \mu \mathrm{L}$ rehydration buffer were loaded onto $11 \mathrm{~cm}, \mathrm{pH}$ 4-7 immobilized $\mathrm{pH}$-gradient strips for the first dimension (isoelectric focusing). In the second dimension, samples were run on $8-16 \%$ gels. Analytical gels were silver stained as described previously [38] and preparative gels were stained using a reversible imidazole-zinc staining procedure. Three analytical gels from wild type and capn $4^{-/-}$MEF cell lysates, plus two mixed sample gels, were used for the image analysis. The gels were scanned with a UMAX PowerLook 1120 scanner (UMAX Technologies) and analysed using ImageMaster 2D Platinum software v5 (GE Healthcare). Differences between the two groups were evaluated by Student's t test with $P<0.05$ indicating the threshold significance level. All significant spots identified with the image analytical software were individually inspected and confirmed. Spots of interest were excised from the preparative gels and digested with trypsin using an in-gel digestion protocol [39]. Prior to mass spectrometry analysis, protein samples were desalted and concentrated using a porous reverse phase R2 material of 20-30 $\mu \mathrm{m}$ bead size (PerSeptive Biosystems) packed in a constricted GELoader column tip (Eppendorf). Peptides were eluted directly onto the target using $0.5 \mu \mathrm{L}$ matrix solution $(5 \mathrm{mg} / \mathrm{mL}$ $\alpha$-cyano-4-hydroxycinnamic acid in 70\% acetonitrile). The proteins were identified with matrix-assisted laser desorption/ionization time-of-flight mass spectrometry; MALDI-TOF-TOF-MS (4700 Proteomics analyzer, Applied Biosystems) [39], using a peptide mass tolerance of $\pm 50 \mathrm{ppm}$ and fragment mass tolerance of \pm 0.5 $\mathrm{kDa}$ as standard settings. Protein identifications were performed with the Mascot database search program and were evaluated with MS/MS as previously described [39].

\section{Statistical methods}

Time lapse data of the proportion (frequency) of blebbing cells were analysed by the Comparison of Proportions method with the Analysis of Frequency procedure and evaluated with the Chi square test. Morphology data by means of F-actin dense areas (base of blebs) was evaluated by Analysis of Frequency with the Chi square and Cochran-Mantel-Haenszel test statistics, all using SAS software (version 8.2). Immunoblots were evaluated by densitometric quantification of the protein bands, and differences were evaluated using Student's t-test 


\section{RESULTS}

\section{Calpain deficient cells displayed reduced membrane blebbing}

Non-apoptotic membrane blebbing is commonly found in various types of cell cultures and accompany physiological processes like cytokinesis and migration [7;9-11]. Adherent cells growing on un-coated glass surfaces display continuous membrane blebbing in the absence of ECM components in the medium [40]. Wild type and capn $4^{-/}$MEFs expressing GFP were compared using time-lapse fluorescence microscopy to test for the morphological differences in these cells when growing on un-coated glass surfaces. Wild type cells displayed a dynamic protrusive morphology, particularly visible at the cell perimeter, characteristic of sporadic membrane blebs. In contrast, capn $4^{-/-}$MEFs displayed significantly less blebbing behaviour (Figure $1 \mathrm{~A}$ and $\mathrm{B})$. The fraction (percentage) of cells exhibiting membrane blebs within the capn $4^{-/}$and wild type MEF populations was quantified by inspection of GFP expressing cells. Statistical evaluation of the occurrence of membrane blebs (in percentage) in more than three independent experiments showed that the fraction of wild type cells displaying sporadic blebs, was significantly higher than that of the capn $4^{-/-}$cells (Figure 1A). Supplementary Movies of the wild type and capn $4^{-1-}$ MEFs shown in Figure 1 are available as SupplMovie1A and SupplMovie1B, respectively, in QuickTime format, and at http://elearning.life.ku.dk/akl/SupplMovie1A and http://elearning.life.ku.dk/akl/SupplMovie1B.

Membrane blebs have been characterized by local actin-dense staining at the base of the blebs, using rhodamine-phalloidin [9;10] and GFP-tagged actin [16]. Actin-dense areas were used to indirectly assess (quantify) the amount of membrane blebs in capn $4^{-1}$ and wild type MEFs by means of TRITC-phalloidin staining of F-actin in fixed cells. Capn $4^{-/-}$and wild type MEFs were scored and ranked by the occurrence of actin-dense areas (Figure 1C), the presence of dense/extended cortical actin, actin foci and amount of stress fibres (not shown). Actin-dense areas were defined as discrete actin patches, mainly at the cell perimeter, with a local staining intensity higher than the cytoplasm, and an appearance different from both smaller actin foci, extended cortical actin and stress fibres. The numbers of actin-dense areas within each cell were counted and the cells were assigned to four categories based on having no (0), very few (1-3), moderate numbers (4-10) or relatively high (>10) numbers of actin-dense areas per cell. The fraction of cells in each of the four groups of the total number of observed cells are shown in Figure 1D. Statistical evaluation of quantified actin-dense areas in the two cell populations indicated that the number of actin-dense areas was higher in wild type MEFs than in capn $4^{-/}$MEFs. These observations, using a more indirect approach, thus confirmed the phenotypic difference revealed by live cell analysis of GFP transfected cells and support the live-cell data indicating that calpain is involved in plasma membrane blebbing.

\section{Expression of m80k-GFP in calpain-deficient cells require co-expression of the small subunit}

To allow a further investigation of the role of calpain in membrane blebbing and to achieve a genetic rescue of calpain in capn $4^{-/}$MEFs, cells were co-transfected with a capn4 expression plasmid encoding the small regulatory subunit, along with a plasmid encoding an m80k-GPF fusion protein. This approach 
facilitated detection of successfully transfected cells, and also provided a direct means to monitor the real time localization and the potential dynamic distribution of m-calpain in living cells.

Expression of the m80k-GFP fusion protein $(107 \mathrm{kDa})$ in capn $^{-/-}$and wild type cells was assessed by immunoblotting using two m-calpain specific antibodies (results with one antibody are shown in Figure 2A). When the cells were transfected with the m80k-pEGFP plasmid alone, m80k-GFP was well expressed in wild type cells, but not in capn $4^{-/-}$MEFs (Figure 2A, lanes 2). However, when cells were co-transfected with m80k-pEGFP and a plasmid encoding the small subunit (28k), expression of the m80k-GFP fusion protein was clearly detected in both wild type and in capn $4^{-/-}$cells (Figure $2 \mathrm{~A}$, lanes 3 ). In contrast, expression of m80k-GFP in wild type fibroblasts was not affected by co-transfection with a plasmid encoding the small subunit (Figure 2A, upper panel). These observations are consistent with the preyious findings when exogenous large and/or small calpain subunits, as well as m80k-GFP, were expressed into Eschericia coli or capn $^{-/}$MEFs $[31 ; 35 ; 36 ; 41 ; 42 ; 43]$. The conclusions of these studies are that an intact small regulatory subunit is required in order for the large catalytic subunits to have enzymatic activity; and co-expression of the small subunit appears to stabilize large subunit expression. Despite the lack of detectable $\mu$ - and $\mathrm{m}$ calpain activities in capn $4^{-/-}$MEFs [3;31] the endogenous m-calpain $80 \mathrm{kDa}$ subunit can still be detected by immunoblotting in these cells, although at significantly lower levels than in wild type cells.

The cellular localization of m80k-GFP and GFP (control) was compared by fluorescence microscopy in capn $4^{-/-}$cells, wild type fibroblasts (Figure $2 \mathrm{~B}$ and $\mathrm{C}$ ) and in $\mathrm{C} 2 \mathrm{C} 12$ myoblasts (not shown). The calpainGFP fusion protein consistently localized diffusely within the cell cytoplasm but was largely restricted from the nucleus. In contrast, GFP localized throughout the cell, including the nucleus.

\section{Genetic rescue of membrane blebbing in calpain - deficient fibroblasts}

To determine if the reduced blebbing observed in capn $4^{-/-}$MEFs was directly linked to calpain deficiency, capn $4^{-/}$MEFs cells were co-transfected with a plasmid encoding the calpain small subunit (28k) and m80k-pEGFP to express m-calpain-GFP, and examined using time-lapse fluorescence microscopy. Membrane blebbing was restored to the wild type level by the genetic rescue of these capn $4^{-/-}$MEFs both under non-stimulated and $\mathrm{Ca}^{2+}$-stimulated conditions (Figure 3A). Representative cells can be seen in Supplementary movie 2 (SupplMovie2; QuickTime) and at: http://elearning.life.ku.dk/ak1/SupplMovie2.

In non-stimulated capr $4^{-/}$MEFs that co-expressed $28 \mathrm{k}$ and m80k-GFP, the fraction of cells exhibiting blebs was approximately the same as in wild type cells expressing GFP and this was significantly higher $(P<$ 0.0001) than capn $4^{-/}$cells expressing GFP alone (Figure $3 \mathrm{~A}$, black bars). The relationship between calpain expression and formation of sporadic membrane blebs was then tested under conditions of elevated intracellular levels of $\mathrm{Ca}^{2+}$. Time-lapse experiments were carried out in the presence of $5 \mu \mathrm{M} \mathrm{Ca}^{2+}$-ionophore A23187 (Figure 3A, grey bars and Supplementary movie 2) and evaluated the same way as for the nonstimulated cells. These experiments confirmed the important points found for non-stimulated cells. The fraction of GFP-expressing cells displaying blebs was significantly higher in the wild type MEFs than in the capn $^{-/-}$population $(P<0.0001)$. Co-expression of $\mathrm{m} 80 \mathrm{k}-\mathrm{GFP}$ and $28 \mathrm{k}$, or GFP and $28 \mathrm{k}$, increased the 
fraction of blebbing cells to levels that were significantly higher $(P<0.0001$ and $P<0.01$, respectively) than found in capn $4^{-/-}$cells expressing GFP alone (Figure 3A, grey bars). Collectively, these data supported a correlation between calpain expression and the formation of sporadic membrane blebs, and showed that reexpression of the small subunit (28k) restored the blebbing phenotype in capn $4^{-/}$cells.

Use of the GFP-tagged (m80k) large subunit allowed us to examine any potential changes in the cellular m-calpain distribution. No clear sign of m-calpain re-localization or trafficking was detected in the time course of these experiments. The stability of m80k-GFP expressed in capn $4^{-/-}$cells was assessed under conditions identical to those used in the $\mathrm{Ca}^{2+}$-stimulated time-lapse experiments to verify that the GFP fusion protein was not autolytically degraded during the time course of the experiments. Immunoblotting of $\mathrm{Ca}^{2+}$ stimulated cells co-transfected with m80k-GFP and $28 \mathrm{k}$ showed that the fusion protein largely remained intact within the 5 - 15 min of A23187-treatment (Supplementary Figure 1).

\section{RhoGDI-1 is down-regulated in calpain-deficient cells}

In order to gain insight into the cellular functions of calpain which might mediate membrane blebbing, a comparison of the protein expression profiles in soluble cell fractions of wild type and capn $4^{-/-}$MEFs was next performed. Image analysis of proteins resolved by two-dimensional electrophoresis (2-DE) revealed several statistically significant quantitative differences in many polypeptides; and fifteen of these were selected for analysis by mass spectrometry (Table 1). This led to the identification of twelve distinct proteins (Table 1, Figure 4A). These were: calpain small subunit (28k); cofilin 1; Rho-GDP dissociation inhibitor 1 (RhoGDI-1); tropomyosin 2 (Tm2: TPM-1, isoform 2); retinoic acid binding protein 1 (CRABP-1); alanyltRNA-synthetase; mannose-6-phosphate receptor binding protein (MPR-BP); thioredoxin-dependent peroxide reductase (AOP-1); elongation initiation factor 5A (eIF-5A); isocitrate dehydrogenase $\alpha$ (IDH3A); endoplasmic reticulum protein precursor (ERp29) and heat-shock protein 70 (HSP-70). Two separate spots for each of the proteins IDH 3A, ERp29 and HSP-70 were found to have changed intensities, and these were subsequently confirmed by MS/MS. Detection of several spots assigned with the same polypeptide identity, were assumed to be due to processing, post-transcriptional modification or the presence different isoforms of these proteins. Three of the twelve proteins; RhoGDI-1, cofilin 1 and tropomyosin have previously been implicated in the dynamic rearrangement of the actin cytoskeleton during membrane protrusion and extensions of blebs and ruffles $[5 ; 12 ; 21 ; 22 ; 44 ; 45]$. Comparison of the mean spot intensities revealed a 2-fold decrease of RhoGDI-1 and a 5-fold increase in the level of fibroblast tropomyosin (Tm2) in capn4 $4^{-/}$MEFs versus wild type cells (Figure 4 and Table 1). As expected, the calpain small (28 kDa) subunit was undetectable in capn $4^{-1}$ MEFs, and cofilin 1 was absent or at least below the detection limit in capn $^{-/-}$MEFs cytoplasmic cell extracts (Figure 4B, C). These findings could reflect changes at the levels of gene expression, protein stability, or possibly differences in the relative proportions of these proteins present in the soluble and insoluble fractions of wild type and capn $4^{-/}$MEFs. Given the roles of cofilin, tropomyosin and RhoGDI- 1 in regulating the actin cytoskeleton, these data are consistent with a role of calpain in contributing to the regulation of membrane blebbing. 
To determine if the observed changes in RhoGDI-1 were directly linked to the lack of functional calpain, the relative expression levels of RhoGDI-1 and endogenous m-calpain large subunit (m80k) in wild type and capn $4^{-/}$cell lysates were next assessed by immunoblotting (Figure 5). Whole-cell lysates as well as cytoplasmic and pellet (insoluble) fractions were investigated from independent cultures of wild type and capn $^{-/}$MEFs. Quantification of the immunoblots showed that the levels of RhoGDI-1 and m80k were significantly lower in capn $4^{-/}$MEFs relative to wild type cells (Figure 5), although the difference in RhoGDI-1 was not as great as the 2.1 fold reduction indicated by the proteomic analysis (Table 1). This reduction was observed in whole cell lysates and in cytoplasmic lysates (Supplementary Figure 2). RhoGDI1 and m80k were nearly undetectable in the pellet fractions of wild type and capn $4^{-/-}$MEFs (not shown), suggesting that translocation to the in insoluble cytoskeletal fraction was not a plausible explanation for the observed decrease of RhoGDI-1 in capn $4^{-/-}$MEFs. Attempts to confirm the decrease in cofilin 1 by immunoblotting were unsuccessful due to cross-reactivity of the tested cofilin 1 antibodies with cofilin 2 , and no attempts were made to confirm the increased level of Tm2 by immunoblotting.

If the reduction in RhoGDI-1 levels was a consequence of calpain deficiency in capn $4^{-/-}$MEFs, it was reasoned that restoring small subunit expression in these cells would also restore Rho-GDI-1 expression. To test this, the levels of RhoGDI-1 and m80k were compared in whole cell lysates prepared from wild type, capn $^{-/}$, and capn $4^{-/}$MEFs transfected with plasmids encoding $28 \mathrm{~K}$ and m80k-GFP. FACS-sorting was used to enrich for the m80k-GFP expressing population in this last group (Figure 5). Knockout and wild type cell lysates from three independent cultures were compared with those expressing m-calpain-GFP after being subjected to FACS-sorting. The level of m80k-GFP was more than 10-fold higher than that of the endogenous m80k subunit in the FACS-sorted transfected capn $4^{-/}$cells, and notably the endogenous m80k subunit was not detectable in this cell population (Figure 5A). Co-expression of the small subunit and m80kGFP in capn $4^{-/}$MEFs resulted in a significant $(P<0.01)$ increase in RhoGDI-1 expression, to approximately 2-fold more than that detected in untransfected capn $4^{-/}$MEFs, and 1.7 fold more than that in wild type cells (Figure 5B). Collectively these data provide strong evidence for a direct relationship between expression of calpain and RhoGDI-1.

\section{DISCUSSION}

Owing to the key roles of calpains in integrin-mediated cell migration and spreading, the majority of reports relating calpain to cell motility have focused on migration. In this study, we investigated the influence of calpain on cell morphology and motility, and found that calpain is required for the formation of sporadic membrane blebs. These spontaneously occurring, apparently non-apoptotic surface extensions were typically smaller and more focal than apoptotic blebs, and often observed in well spread wild type fibroblasts, but were much less frequent in the calpain-deficient cells. Calpain activity has previously been associated with bleb formation during apoptosis and disturbances of $\mathrm{Ca}^{2+}$-homeostasis in oxidative stressed hepatocytes [46]. Howeyer, apoptotic blebs are usually much larger, more homogeneous in size, and are strongly associated with cell retraction and a round morphology [9]. Rescue of calpain expression in capn ${ }^{-/}$MEFs completely restored the blebbing phenotype, and increased the expression of RhoGDI-1 to approximately 2-fold above 
the level of wild type cells. Our data indicate that calpain regulates formation of membrane blebs and establishes a novel connection between calpain and RhoGDI-1, suggesting that these proteins may have linked roles in formation of membrane blebs. The blebbing behaviour was not unambiguously stimulated by calcium ionophore. This suggests that the influx of extracellular calcium associated with ionophore treatment is not responsible for initiating the calpain activity associated with blebbing.

Calpain-associated blebbing was identified by live cell studies of $c a p n 4^{-/}$and wild type MEFs cultured under conditions of low integrin-dependent cell migration, with cells grown on non-coated glass surfaces. Previous studies of these cells, performed under conditions of stimulated integrin-signalling using fibronectin-coated (FN) surfaces demonstrated impaired migration rates, abnormal cytoskeletal organization, reduced numbers of focal adhesions, and diminished cleavage of spectrin and talin [3]. Moreover, lamellipod protrusion was improperly regulated in capn $4^{-/}$MEFs and in wild type cells which have had $\mathrm{m}$-calpain knocked down, compared to wild type MEFs [47]. These previous observations are consistent with our findings, and together these data support the idea that small, transient membrane extensions like blebs and ruffles are involved in cell migration, and may represent an integral part of the motile behaviour of certain cell types, regulated by both extrinsic physical and intrinsic biochemical signals. The reduced blebbing found in capn $4^{-/}$cells was restored by co-transfection with expression plasmids encoding the small subunit along with an m80k-GPF expression plasmid to facilitate assessment of the transfected cell population. Incomplete calpain rescue in capn $^{-/-}$MEFs transfected with the two 28k-expression vectors used in this study (pSBC-28k and pMSCV$28 \mathrm{k}$ ) is fully consistent with our earlier findings. It therefore seems likely that co-expression with m80k-GFP enhanced the stability of $28 \mathrm{k}$ expression in the capn $4^{-/}$MEFs, and this resulted in a more complete restoration of calpain activity and blebbing behaviour. The experiments done here do not distinguish between the involvements of $\mathrm{m}$ - and $\mu$-calpain in the blebbing phenotype. Rescue of small subunit expression has been shown to restore both $\mathrm{m} 80 \mathrm{k}$ and $\mu 80 \mathrm{k}$ subunit expression, and restore both $\mathrm{m}$ - and $\mu$-calpain activites to capn4 ${ }^{-/}$MEFs [31]. RNA knockdown experiments showed that lamellipodial dynamics were disrupted in cells deficient in the m80k, but not $\mu 80 \mathrm{k}$ subunit [47]. While this supports a tentative conclusion that it is loss of m-calpain that caused the blebbing defect observed here; we can not exclude the possible involvement of $\mu$-calpain.

Proteome analysis of the calpain-deficient cells revealed significant alterations in the level of several proteins, including the calpain $28 \mathrm{kDa}$ subunit itself. The identification of RhoGDI-1, cofilin 1 and Tm2 was of particular interest, because of their previously defined roles as regulators of the cytoskeleton during the formation of lamellipodia, membrane ruffles and blebs [4;5;12;21;22;44;45;48;49]. The level of RhoGDI-1 was 2-fold reduced and cofilin 1 was virtually eliminated, whereas Tm2 was 5-fold increased, suggesting its potential up-regulation or increased stability in the cytoplasm of calpain knockout cells. Tropomyosin and cofilin both regulate actin filament turnover and network dynamics by their mutually exclusive binding to Factin [21]. Cofilin is essential for both actin filament turnover and polymerization. The severing activity of 
cofilin, which creates free barbed ends, has been found to promote lamellipodium extension and to set the direction of cell motility in rat mammary carcinoma (MTLn3) cells [22]. Tropomyosin antagonizes cofilin and stabilizes F-actin [21;22]. Recent studies indicates a connection between the regulation of blebs or lamellipodium formation, a disturbed tropomyosin expression [12;45] and tropomyosin phosphorylation [49]. In addition, active non-phosphorylated cofilin (S3A-cofilin) was found co-localized with actin and Arp2/3 in apoptotic blebs, suggesting a role of cofilin in formation of these structures [48]. However, the precise mechanisms by which cofilin and tropomyosin contribute to blebbing remain to be established. Interestingly, we observed reduced membrane blebbing and a concurrent decreased level of cofilin in the capn $^{-/}$MEFs. Our observations that changed levels of tropomyosin, cofilin and RhoGDI-1 coincided with markedly reduced blebbing in calpain-deficient cells were intriguing, and may suggest a connection between these proteins and calpain in cell motility. The finding that co-expression of $28 \mathrm{k}$ and m80k-GFP in capn $4^{-/-}$ cells correlated with RhoGDI-1 over-expression suggests a regulatory relationship between calpain and RhoGDI-1. The observed changes in cofilin 1 and tropomyosin expression were not further investigated here; clearly this merits future studies. RhoGDIs (1,2 and 3) are key regulators of Rho-GTPases through their capacity to bind and maintain them in a cytoplasmic, inactive GDP-bound state [4;5]. RhoGDIs inhibit the dissociation of GDP, regulate the GTPase membrane-cytosolic cycling, and prevent interaction of RhoGTPases with regulatory and effector molecules (e.g. ROCK). The phosphorylation of RhoGDI-1 by PKC $\alpha$ and PAK has been reported to activate RhoA and Rac [50], and several PKC isoenzymes are also calpain substrates in vitro [26]. These findings suggest a potential regulatory link between calpain and RhoGDI-1. In addition, consistent with a role of calpain in promoting caspase-12, -9 and -3 mediated ER stress-induced apoptosis [35], it is possible that activation of ROCK by caspase-3, which induces MLC-mediated blebbing in apoptotic and non-apoptotic cells, could be calpain-regulated. Given the technical limitations of the proteomic methods used in this study, we would not expect to observe and identify all the changes occurring in the proteome as a result of calpain deficiency. Indeed, the fifteen proteins identified here is likely to be just a subset of the total changes. The fact that the $\mu 80 \mathrm{k}$ and m80k catalytic subunits were not identified as differentially expressed proteins verifies these apparent limitations, since it has been previously shown by immunoblotting analysis that the steady state levels of these two proteins are reduced in capn $4^{-/}$MEF [31;35].

In summary, this study provides novel evidence linking calpain to regulation of membrane blebbing and identifies RhoGDI-1, cofilin and tropomyosin as potential downstream mediators of this intriguing cellular behaviour. The relationship between blebbing and cell migration is not well understood, but it is interesting that calpain has now been implicated in the regulation of both phenomena. This observation, and the identification of three actin regulators whose expression is linked to calpain, may lead to new insights about the regulation of cytoskeletal remodelling during these processes. 


\section{ACKNOWLEDGMENTS}

The authors gratefully acknowledge Dr. Bent Aasted, Department of Veterinary Pathobiology (Faculty of Life Sciences, University of Copenhagen) for flow cytometry analysis of GFP transfectants. We also wish to thank Dr. Peter Schjerling, Copenhagen Muscle Research Centre for the pEGFP-N1 vector and helpful advice, Teresa B. Farré for excellent technical assistance and Dr. Ib Skovgaard, Department of Natural Sciences (Faculty of Life Sciences, University of Copenhagen) for supervision on statistical analyses. This work was supported by the Danish Agricultural and Veterinary Research Council and a grant from the Canadian Institutes of Health Research. 


\section{Reference List}

1 Huttenlocher, A., Palecek, S. P., Lu, Q., Zhang, W., Mellgren, R. L., Lauffenburger, D. A., Ginsberg, M. H. and Horwitz, A. F. (1997) Regulation of cell migration by the calcium-dependent protease calpain. J. Biol. Chem. 272, 32719-32722

2 Potter, D. A., Tirnauer, J. S., Janssen, R., Croall, D. E., Hughes, C. N., Fiacco, K. A., Mier, J. W., Maki, M. and Herman, I. M. (1998) Calpain regulates actin remodeling during cell spreading. J. Cell Biol. 141, 647-662

3 Dourdin, N., Bhatt, A. K., Dutt, P., Greer, P. A., Arthur, J. S. C., Elce, J. S. and Huttenlocher, A. (2001) Reduced cell migration and disruption of the actin cytoskeleton in calpain-deficient embryonic fibroblasts. Journal of Biological Chemistry 276, 48382-48388

4 Burridge, K. and Wennerberg, K. (2004) Rho and Rac take center stage. Cell 116, 167-179

5 DerMardirossian, C. and Bokoch, G. M. (2005) GDIs: central regulatory molecules in Rho GTPase activation. Trends Cell Biol. 15, 356-363

6 Grinnell, F. (1982) Migration of human neutrophils in hydrated collagen lattices. J. Cell Sci. 58, 95-108

7 Sahai, E. and Marshall, C. J. (2003) Differing modes of tumour cell invasion have distinct requirements for Rho/ROCK signalling and extracellular proteolysis. Nat. Cell Biol. 5, 711-719

8 Mills, J. C., Stone, N. L., Erhardt, J. and Pittman, R. N. (1998) Apoptotic membrane blebbing is regulated by myosin light chain phosphorylation. J. Cell Biol. 140, 627-636

9 Laster, S. M. and Mackenzie, J. M., Jr. (1996) Bleb formation and F-actin distribution during mitosis and tumor necrosis factor-induced apoptosis. Microsc. Res. Tech. 34, 272-280

10 Fishkind, D. J., Cao, L. G. and Wang, Y. L. (1991) Microinjection of the catalytic fragment of myosin light chain kinase into dividing cells: effects on mitosis and cytokinesis. J. Cell Biol. 114, 967-975

11 Trinkaus, J. P. (1973) Surface activity and locomotion of Fundulus deep cells during blastula and gastrula stages. Dev. Biol. 30, 69-103

12 Gupton, S. L., Anderson, K. L., Kole, T. P., Fischer, R. S., Ponti, A., Hitchcock-DeGregori, S. E., Danuser, G., Fowler, V. M., Wirtz, D., Hanein, D. and Waterman-Storer, C. M. (2005) Cell migration without a lamellipodium: translation of actin dynamics into cell movement mediated by tropomyosin. J. Cell Biol. 168, 619-631

13 Jewell, S. A., Bellomo, G., Thor, H., Orrenius, S. and Smith, M. (1982) Bleb formation in hepatocytes during drug metabolism is caused by disturbances in thiol and calcium ion homeostasis. Science 217, 1257-1259

14 Lemasters, J. J., DiGuiseppi, J., Nieminen, A. L. and Herman, B. (1987) Blebbing, free Ca2+ and mitochondrial membrane potential preceding cell death in hepatocytes. Nature 325, 78-81

15 Keller, H. and Eggli, P. (1998) Protrusive activity, cytoplasmic compartmentalization, and restriction rings in locomoting blebbing Walker carcinosarcoma cells are related to detachment of cortical actin from the plasma membrane. Cell Motil. Cytoskeleton 41, 181-193 
16 Charras, G. T., Yarrow, J. C., Horton, M. A., Mahadevan, L. and Mitchison, T. J. (2005) Nonequilibration of hydrostatic pressure in blebbing cells. Nature 435, 365-369

17 Riento, K. and Ridley, A. J. (2003) Rocks: multifunctional kinases in cell behaviour. Nat. Rev. Mol. Cell Biol. 4, 446-456

18 Coleman, M. L., Sahai, E. A., Yeo, M., Bosch, M., Dewar, A. and Olson, M. F. (2001) Membrane blebbing during apoptosis results from caspase-mediated activation of ROCK I. Nat. Cell Biol. 3 , 339-345

19 Sebbagh, M., Renvoize, C., Hamelin, J., Riche, N., Bertoglio, J. and Breard, J. (2001) Caspase-3mediated cleavage of ROCK I induces MLC phosphorylation and apoptotic membrane blebbing. Nat. Cell Biol. 3, 346-352

20 Arber, S., Barbayannis, F. A., Hanser, H., Schneider, C., Stanyon, C. A., Bernard, O. and Caroni, P. (1998) Regulation of actin dynamics through phosphorylation of cofilin by LIM-kinase. Nature 393, 805-809

21 DesMarais, V., Ghosh, M., Eddy, R. and Condeelis, J. (2005) Cofilin takes the lead. J. Cell Sci. 118, $19-26$

22 Ghosh, M., Song, X., Mouneimne, G., Sidani, M., Lawrence, D. S. and Condeelis, J. S. (2004) Cofilin promotes actin polymerization and defines the direction of cell motility. Science 304, 743746

23 Beckerle, M. C., Burridge, K., Demartino, G. N. and Croall, D. E. (1987) Colocalization of Calcium-Dependent Protease-Ii and One of Its Substrates at Sites of Cell-Adhesion. Cell 51, 569577

24 Bialkowska, K., Kulkarni, S., Du, X., Goll, D. E., Saido, T. C. and Fox, J. E. (2000) Evidence that beta3 integrin-induced Rac activation involves the calpain-dependent formation of integrin clusters that are distinct from the focal complexes and focal adhesions that form as Rac and RhoA become active. J. Cell Biol. 151, 685-696

25 Carragher, N. O., Levkau, B., Ross, R. and Raines, E. W. (1999) Degraded collagen fragments promote rapid disassembly of smooth muscle focal adhesions that correlates with cleavage of pp125(FAK), paxillin, and talin. J. Cell Biol. 147, 619-630

26 Kishimoto, A., Mikawa, K., Hashimoto, K., Yasuda, I., Tanaka, S., Tominaga, M., Kuroda, T. and Nishizuka, Y. (1989) Limited Proteolysis of Protein Kinase-C Subspecies by Calcium-Dependent Neutral Protease (Calpain). Journal of Biological Chemistry 264, 4088-4092

27 Kulkarni, S., Goll, D. E. and Fox, J. E. (2002) Calpain cleaves RhoA generating a dominantnegative form that inhibits integrin-induced actin filament assembly and cell spreading. J. Biol. Chem. 277, 24435-24441

28 Ito, M., Tanaka, T., Nunoki, K., Hidaka, H. and Suzuki, K. (1987) The Ca2+ -activated protease (calpain) modulates $\mathrm{Ca} 2+/$ calmodulin dependent activity of smooth muscle myosin light chain kinase. Biochem. Biophys. Res. Commun. 145, 1321-1328

29 Ariyoshi, H., Shiba, E., Sakon, M., Kambayashi, J., Yoshida, K., Kawashima, S. and Mori, T. (1993) Translocation of human platelet calpain-I. Biochem. Mol. Biol. Int. 30, 63-72 
30 Molinari, M., Anagli, J. and Carafoli, E. (1994) $\mathrm{Ca}(2+)$-activated neutral protease is active in the erythrocyte membrane in its nonautolyzed 80-kDa form. J. Biol. Chem. 269, 27992-27995

31 Arthur, J. S., Elce, J. S., Hegadorn, C., Williams, K. and Greer, P. A. (2000) Disruption of the murine calpain small subunit gene, Capn4: calpain is essential for embryonic development but not for cell growth and division. Mol. Cell Biol. 20, 4474-4481

32 Azam, M., Andrabi, S. S., Sahr, K. E., Kamath, L., Kuliopulos, A. and Chishti, A. H. (2001) Disruption of the mouse mu-calpain gene reveals an essential role in platelet function. Mol. Cell Biol. 21, 2213-2220

33 Dutt, P., Croall, D. E., Arthur, S. C., De Veyra, T., Williams, K., Elce, J. S. and Greer, P. A. (2006) $\mathrm{m}$-Calpain is required for preimplantation embryonic development in mice. BMC. Dev. Biol. 6, 3

34 Zimmerman, U. J., Boring, L., Pak, J. H., Mukerjee, N. and Wang, K. K. (2000) The calpain small subunit gene is essential: its inactivation results in embryonic lethality. IUBMB. Life 50, 63-68

35 Tan, Y., Dourdin, N., Wu, C., De Veyra, T., Elce, J. S. and Greer, P. A. (2006) Ubiquitous calpains promote caspase-12 and Jnk activation during ER stress-induced apoptosis. J. Biol. Chem.

36 Elce, J. S., Hegadorn, C., Gauthier, S., Vince, J. W. and Davies, P. L. (1995) Recombinant calpain II: improved expression systems and production of a C105A active-site mutant for crystallography. Protein Eng 8, 843-848

37 Samis, J. A., Back, D. W., Graham, E. J., DeLuca, C. I. and Elce, J. S. (1991) Constitutive expression of calpain II in the rat uterus during pregnancy and involution. Biochem. J. 276 ( Pt 2), 293-299

38 Lametsch, R. and Bendixen, E. (2001) Proteome analysis applied to meat science: characterizing postmortem changes in porcine muscle. J. Agric. Food Chem. 49, 4531-4537

39 Jensen, O. N., Larsen, M. R. and Roepstorff, P. (1998) Mass spectrometric identification and microcharacterization of proteins from electrophoretic gels: Strategies and applications. ProteinsStructure Function and Genetics 74-89

40 Sugrue, S. P. and Hay, E. D. (1981) Response of basal epithelial cell surface and Cytoskeleton to solubilized extracellular matrix molecules. J. Cell Biol. 91, 45-54

41 Larsen, A. K., De Veyra, T., Jia, Z. C., Wells, A., Dutt, P. and Elce, J. S. (2004) Expression of human, mouse, and rat m-calpains in Escherichia coli and in murine fibroblasts. Protein Expression and Purification 33, 246-255

42 Graham-Siegenthaler, K., Gauthier, S., Davies, P. L. and Elce, J. S. (1994) Active recombinant rat calpain II. Bacterially produced large and small subunits associate both in vivo and in vitro. J. Biol. Chem. 269, 30457-30460

43 Elce, J. S., Davies, P. L., Hegadorn, C., Maurice, D. H. and Arthur, J. S. (1997) The effects of truncations of the small subunit on m-calpain activity and heterodimer formation. Biochem. J. 326 (Pt 1), 31-38

44 Aizawa, H., Sutoh, K. and Yahara, I. (1996) Overexpression of cofilin stimulates bundling of actin filaments, membrane ruffling, and cell movement in Dictyostelium. J. Cell Biol. 132, 335-344 
45 Wong, K., Wessels, D., Krob, S. L., Matveia, A. R., Lin, J. L., Soll, D. R. and Lin, J. J. (2000) Forced expression of a dominant-negative chimeric tropomyosin causes abnormal motile behavior during cell division. Cell Motil. Cytoskeleton 45, 121-132

46 Nicotera, P., Hartzell, P., Davis, G. and Orrenius, S. (1986) The formation of plasma membrane blebs in hepatocytes exposed to agents that increase cytosolic $\mathrm{Ca} 2+$ is mediated by the activation of a non-lysosomal proteolytic system. FEBS Lett. 209, 139-144

47 Franco, S., Perrin, B. and Huttenlocher, A. (2004) Isoform specific function of calpain 2 in regulating membrane protrusion. Experimental Cell Research 299, 179-187

48 Mannherz, H. G., Gonsior, S. M., Gremm, D., Wu, X., Pope, B. J. and Weeds, A. G. (2005) Activated cofilin colocalises with Arp2/3 complex in apoptotic blebs during programmed cell death. Eur. J. Cell Biol. 84, 503-515

49 Houle, F., Rousseau, S., Morrice, N., Luc, M., Mongrain, S., Turner, C. E., Tanaka, S., Moreau, P. and Huot, J. (2003) Extracellular signal-regulated kinase mediates phosphorylation of tropomyosin-1 to promote cytoskeleton remodeling in response to oxidative stress: impact on membrane blebbing. Mol. Biol. Cell 14, 1418-1432

50 DerMardirossian, C., Schnelzer, A. and Bokoch, G. M. (2004) Phosphorylation of RhoGDI by Pak1 mediates, dissociation of Rac GTPase. Molecular Cell 15, 117-127 
Table 1

\begin{tabular}{|c|c|c|c|c|c|c|c|}
\hline $\begin{array}{l}\text { spot } \\
\text { no. }\end{array}$ & Protein name / protein ID & $\begin{array}{c}\text { Swiss-Prot } \\
\text { Accession } \\
\text { numbers }\end{array}$ & $\begin{array}{c}M w \\
(k D a)\end{array}$ & $\begin{array}{c}\text { Sequence } \\
\text { Coverage } \\
(\%)\end{array}$ & $\begin{array}{c}\text { No. } \\
\text { Match } \\
\text { peptides }\end{array}$ & $\begin{array}{l}\text { No. of } \\
\text { signific. } \\
\text { MS/MS } \\
\text { peptides }\end{array}$ & $\begin{array}{c}\text { Fold increase } \\
(\uparrow) \text { or } \\
\text { decrease }(\downarrow) \\
\text { relative to } \\
\text { wild type cells }\end{array}$ \\
\hline 1 & calpain small subunit & O88456 & 28 & $32 \%$ & & 2 & $* \downarrow$ \\
\hline 2 & cofilin 1, non-muscle isoform: COF1 & P18760 & 19 & $62 \%$ & 9 & 3 & $* \downarrow$ \\
\hline 3 & retinoic acid binding protein: CRABP-1 & P02695 & 16 & $70 \%$ & 12 & 6 & $* \downarrow$ \\
\hline 4 & alanyl-tRNA- synthetase & Q8BGQ7 & 108 & $42 \%$ & 27 & 7 & $2.6 \downarrow$ \\
\hline 5 & $\begin{array}{l}\text { mannose-6-phos. receptor binding protein: } \\
\text { MPR-BP }\end{array}$ & Q8BKV9 & 47 & $74 \%$ & 21 & 7 & $2.3 \downarrow$ \\
\hline 6 & Rho-GDP dissociation inhibitor 1: RhoGDI-1 & Q99PT1 & 23 & $67 \%$ & 11 & 6 & $2.1 \downarrow$ \\
\hline 7 & $\begin{array}{l}\text { Fibroblast tropomyosin, isoform 2: Tm2 } \\
\text { (tropomyosin } 1(\alpha) \text {; TPM-1, isoform } 2 \text { ) }\end{array}$ & P58771 & 33 & $19 \%$ & 4 & 1 & $5.4 \uparrow$ \\
\hline 8 & $\begin{array}{l}\text { thioredoxin-depend. peroxide reductase: } \\
\text { AOP-1 }\end{array}$ & P20108 & 28 & $38 \%$ & 7 & 1 & $2.4 \uparrow$ \\
\hline 9 & elongation initiation factor 5A: eIF-5A & P10159 & 17 & $21 \%$ & 5 & 2 & $1.8 \uparrow$ \\
\hline 10 & $\begin{array}{l}\text { isocitrate dehydrogenase } \alpha \text {, mit. precursor: } \\
\text { IDHA }\end{array}$ & Q28480 & 38 & $33 \%$ & 12 & 8 & $2.4 \downarrow$ \\
\hline 11 & isocitrate dehydrogenase $3 \alpha$ : IDH $3 \mathrm{~A} * *$ & NP 083849 & 40 & $30 \%$ & 9 & 2 & $2.5 \uparrow$ \\
\hline 12 & $\begin{array}{l}\text { endoplasmic reticulum protein precursor: } \\
\text { ERp29 }\end{array}$ & P57759 & 29 & $22 \%$ & 6 & 1 & $9.0 \downarrow$ \\
\hline 13 & $\begin{array}{l}\text { endoplasmic reticulum protein precursor: } \\
\text { ERp29 }\end{array}$ & P57759 & 29 & $40 \%$ & 7 & 5 & $2.3 \uparrow$ \\
\hline 14 & heat-shock protein 70: HSP70 & P38647 & 73 & $37 \%$ & 17 & 7 & $6.3 \downarrow$ \\
\hline 15 & heat-shock protein 70 : HSP 70 & P38647 & 73 & $33 \%$ & 15 & 5 & $6.3 \uparrow$ \\
\hline
\end{tabular}

Table 1: Protein identification data from mass spectrometry and 2D-gels of capn $^{-/-}$and wild type cells. Proteins were identified based on the differential expression pattern in triplicate cytoplasmic lysates of capn $4^{-/-}$and $\operatorname{capn} 4^{+/+}$MEF cultures. Fifteen different spots were found significantly changed $(P<0.05)$ by image analysis and twelve different proteins were correspondingly identified by mass spectrometry and the Mascot database search engine. From the left side, spot numbers, protein names and Swiss-Prot ID numbers are listed followed by predicted molecular weight, the sequence coverage, numbers of match peptides and the number of peptides subjected to MS/MS, which were used for the identification are listed. The approximate fold-change of each protein is listed in the far right column. Arrows pointing up or down indicates fold increase or decrease, respectably of the given protein relative to wild type cells. 


\section{FIGURE LEGENDS}

Figure 1: Reduced membrane blebbing activity in calpain-deficient cells.

Time-lapse fluorescence microscopy of (A) wild type $\left(\operatorname{capn}^{+/ /}\right)$, and (B) calpain knockout $\left(\right.$capn $\left.^{-/-}\right)$ immortalized mouse embryonic fibroblasts expressing GFP. Four frames of a twenty frame image series are shown. White arrows indicate sites of sporadic membrane blebs. Bars represent $10 \mu \mathrm{m}$. (C) Phallodin staining of actin-dense areas in single cells, which likely correspond to the base of blebs, was used to quantify the amount of blebbing (in \%) in the wild type (left panel) and calpain knockout (right panel) MEF populations. (D) The percentages of cells with no (0), very few (1-3), moderate numbers (4-10) or high $(>10)$ numbers of actin-dense sites per cell was evaluated. The numbers of actin-dense areas/sites per cell was significantly higher $(P<0.001)$ in wild type cells $(n=156)$ than in calpain-deficient cells $(n=167)$.

Figure 2: Ectopically expressed m80k-GFP is cytoplasmic and depends on co-expression with exogenous small subunit in calpain-deficient but not in wild type MEFs.

(A) Immunoblotting analysis of wild type (upper panel) and capn $4^{-/-}$(lower panel) cells expressing m80kGFP in the presence or absence of exogenous small $(28 \mathrm{kDa})$ subunit. Lane 1: Untransfected cells, Lane 2: Cells transfected with m80k-pEGFP, Lane 3: Cells co-transfected with m80k-pEGFP and 28k-pMSCV (RP2 antibody was used). Transfection efficiencies of wild type cells were generally slightly lower than capn $4^{-/-}$ cells. (B) Fluorescence microscopy of capn $4^{-/-}$MEFs that co-express $28 \mathrm{k}$ and m80k-GFP and (C) GFP control. Bars represent $10 \mu \mathrm{m}$. The images were obtained 24 hrs post transfection.

Figure 3: Reduced membrane blebbing in calpain-deficient cells is restored to wild type levels by ectopically co-expression of the calpain $28 \mathrm{k}$ subunit and $\mathrm{m} 80 \mathrm{k}$-GFP.

Membrane blebbing of non-stimulated and $\mathrm{Ca}^{2+}$-ionophore stimulated wild type and capn $4^{-/-}$MEFs expressing GFP, co-expressing $28 \mathrm{k}$ and GFP or $28 \mathrm{k}$ and m80k-GFP (m-calpain-GFP) was monitored by time-lapse fluorescence microscopy. Quantification of membrane blebbing was evaluated as the fraction of cells displaying blebs of the total number (n) of observed cells (in \%). (A) Black and grey columns, arranged pair wise represents the non-stimulated and $\mathrm{Ca}^{2+}$-ionophore treated cells, respectively. Columns 1 and 2 : Wild type cells expressing GFP $(n=39$ and $n=33)$; columns 3 and 4: Capn $4^{-/ /}$cells expressing GFP $(n=64$ and $n=72)$; columns 5 and 6: Capn $4^{-/-}$cells co-expressing $28 \mathrm{k}$ and GFP $(\mathrm{n}=20$ and $\mathrm{n}=41)$; column 7 and 8: $\mathrm{Capn}^{-/-}$cells co-expressing m80k-GFP and $28 \mathrm{k}(\mathrm{n}=66$ and $\mathrm{n}=52)$. Bars represent standard errors. Columns with distinct letters $(\mathrm{a}, \mathrm{b}, \mathrm{c})$ are significantly different; columns labelled a and $\mathrm{c}(P<0.0001)$ and columns marked a and b $(P<0.01)$. (B) Live cell fluorescence microscopy of capn $4^{-/}$cells co-expressing m80k-GFP and $28 \mathrm{k}$. Four frames of a twenty frame image series (recorded within $10 \mathrm{~min}$ ) collected after addition of A23187 are shown. Bars represent $10 \mu \mathrm{m}$.

Figure 4: Differential expression of RhoGDI-1, cofilin 1 and tropomyosin 2 in calpain-deficient versus wild type fibroblasts.

(A) Two-dimensional gel electrophoresis of a mixed gel showing the location of the twelve distinct proteins with altered cytoplasmic expression patterns in capn $4^{-/}$versus wild type MEFs, identified by mass spectrometry. (B) RhoGDI-1, cofilin 1, tropomyosin (Tm2) and calpain small subunit (28k) spots were differentially expressed on the two representative gels with wild type and capn ${ }^{-/}$cell lysates. (C) Quantification of the relative spot intensities of RhoGDI-1, cofilin 1, Tm2 and calpain 28k were significantly different $(P<0.05)$ between the genotypes. Bars represent standard errors from three gels of each genotype. 
Figure 5: Diminished RhoGDI-1 expression in calpain-deficient cells was rescued by co-expression of calpain $28 \mathrm{k}$ subunit and m80k-GFP.

Immunoblotting analysis to detect and quantify m-calpain and RhoGDI-1 in whole cell lysates of wild type and capn $^{-/-}$triplicate cell cultures and a GFP-positive FACS-sorted population of capn $4^{-/}$MEFs after cotransfection with plasmids encoding the calpain small subunit and m80k-GFP. (A) A representative immunoblot showing endogenous $\mathrm{m} 80 \mathrm{k}$ and exogenous m80k-GFP (RP2 antibody). Densitometry analysis indicates that levels of the endogenous m80k subunit were about 2-fold higher in wild type (Lanes 1-3) than in capn $4^{-/-}$MEFs (Lanes 4-6). Comparison with FACS-sorted capn ${ }^{-/}$MEFs expressing m80k-GFP shows that the level of m80k-GFP (Lanes 7-8) was at least 10-fold higher than the level of endogenous m80k in both cell types. The faint faster migrating band in lanes 7 and 8 likely represents a cleavage product of the m80k-GFP protein; and interestingly, the endogenous $\mathrm{m} 80 \mathrm{k}$ protein was not detected in these cells. The relevant lanes shown were cropped in sections (Lanes 1-3, 4-6 and 7-8) from a larger gel image. (B) Top: The m-calpain immunoblot was stripped and reprobed to detect RhoGDI-1. A representative blot is shown, with the same sections cropped as in (A). (B) Bottom: Relative RhoGDI-1 levels were assessed by densitometry analysis of RhoGDI-1 band intensities in three independent experiments. Columns with distinct letters $(\mathrm{a}, \mathrm{b}, \mathrm{c})$ are significantly different $(P<0.01)$. Bars represent standard errors. 
Figure 1

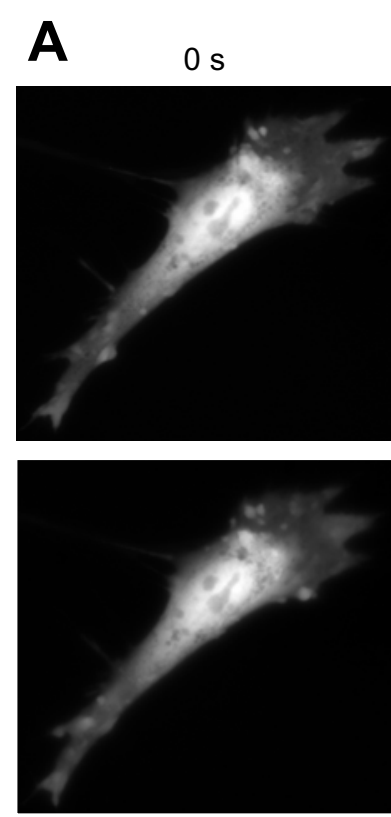

$120 \mathrm{~s}$

C

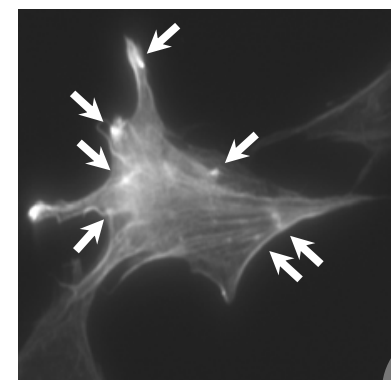

$60 \mathrm{~s}$
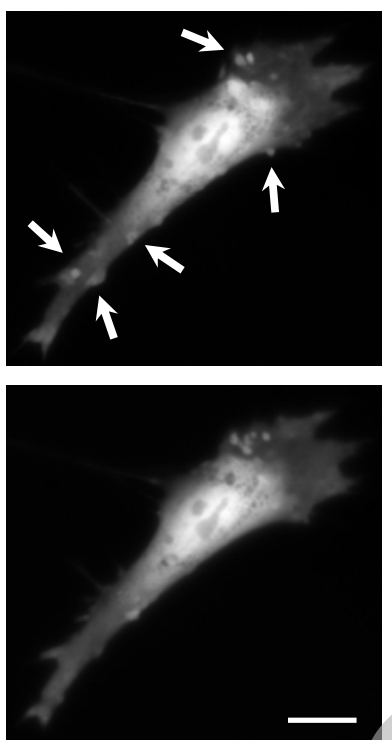

$300 \mathrm{~s}$
B
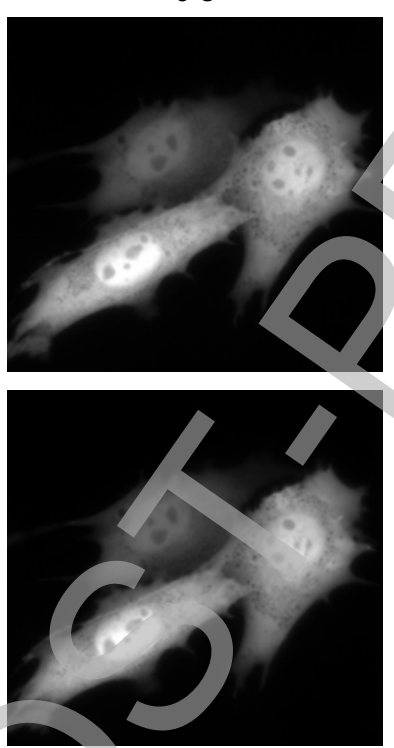

$120 \mathrm{~s}$
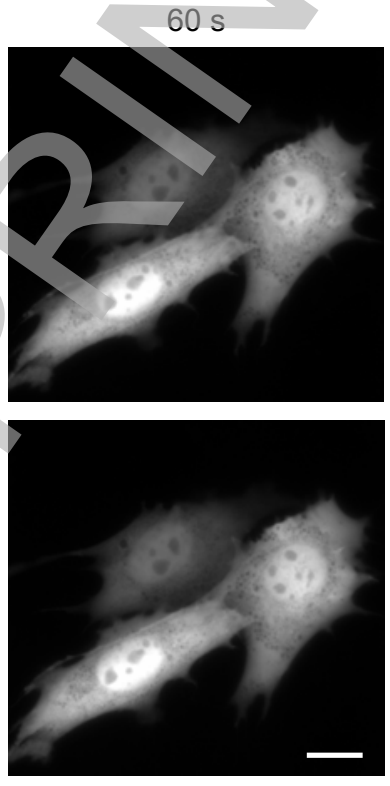

$300 \mathrm{~s}$

\section{D}

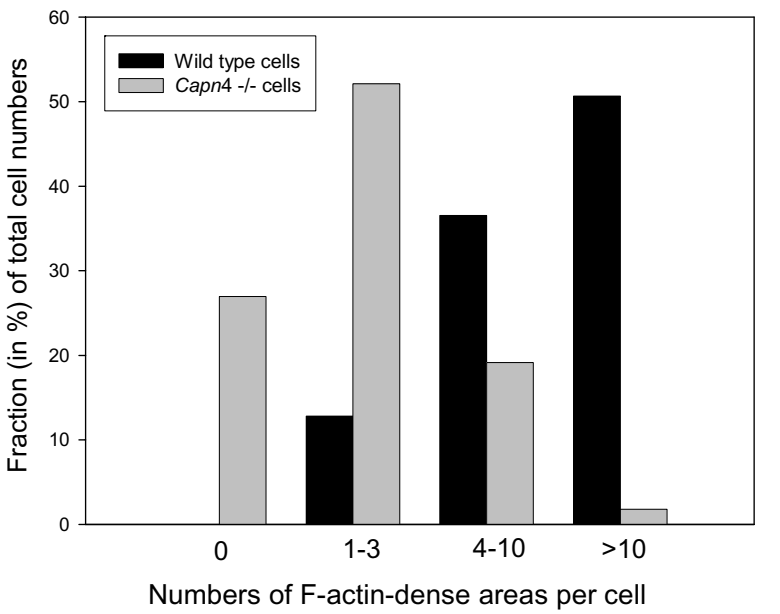


Figure 2
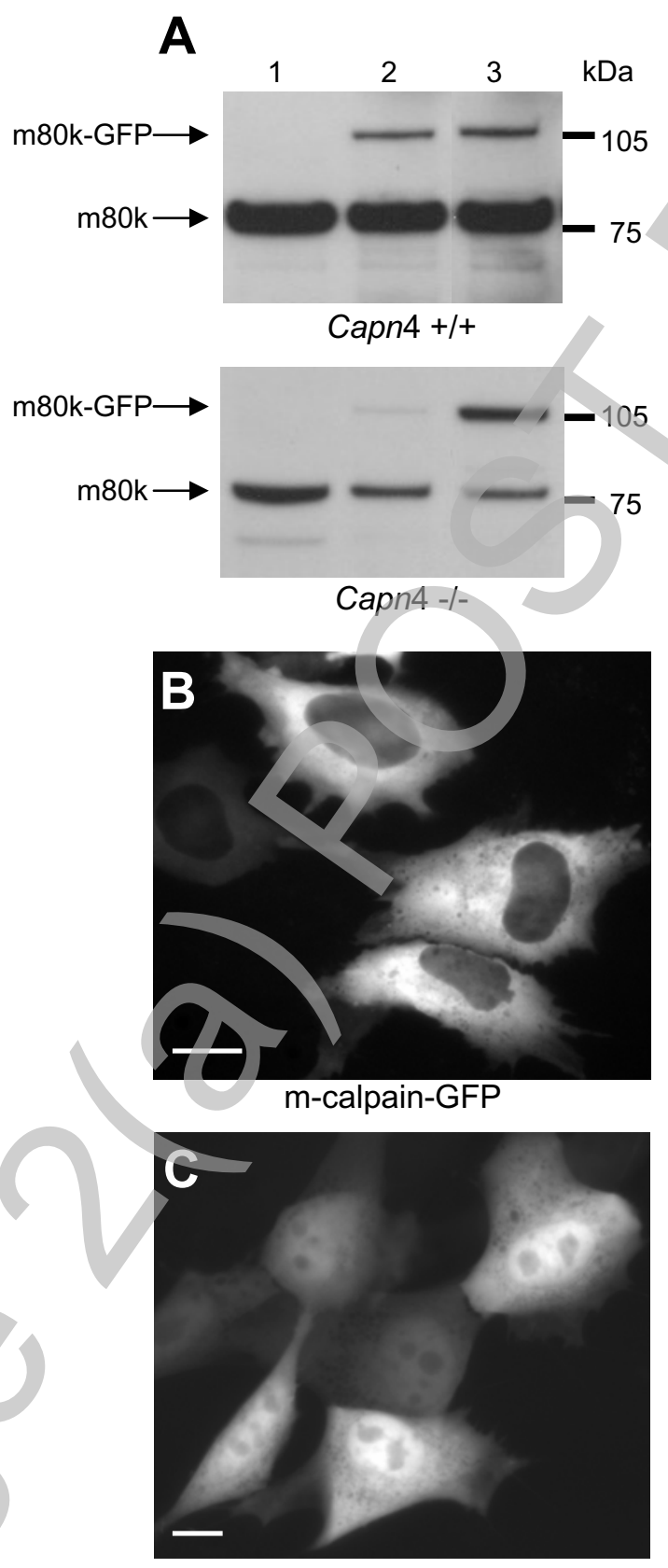


\section{Figure 3}

\section{A}

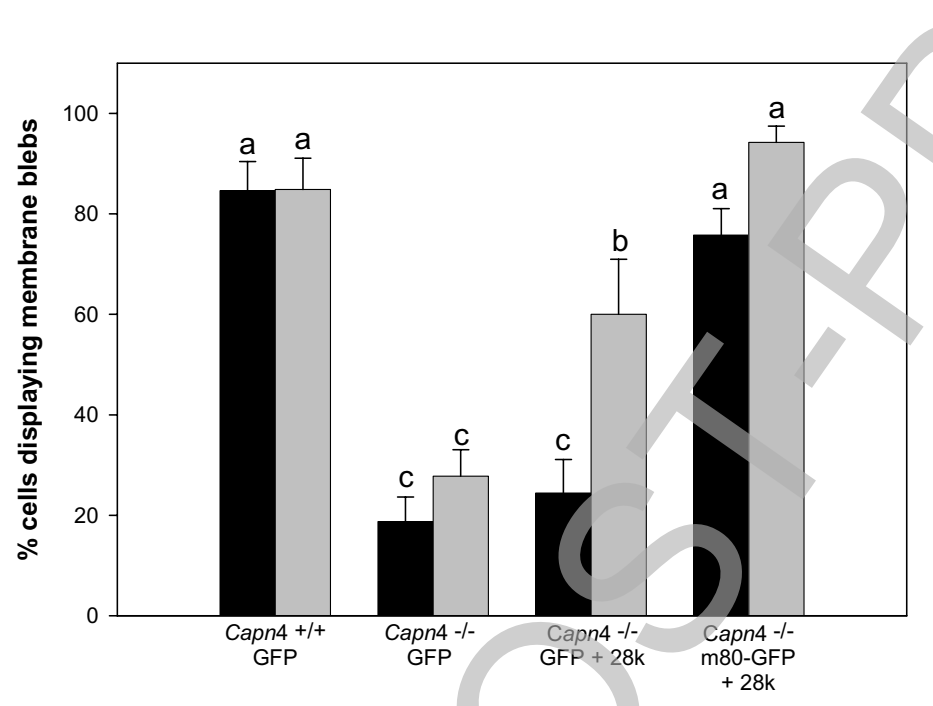

B
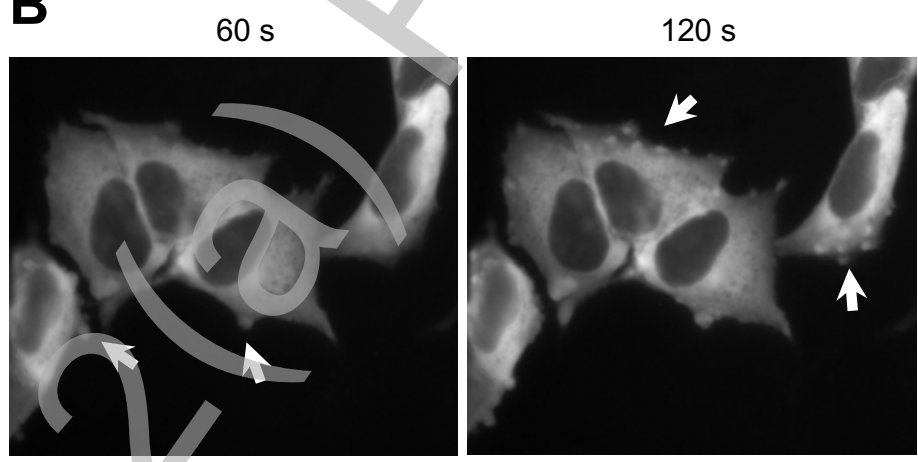

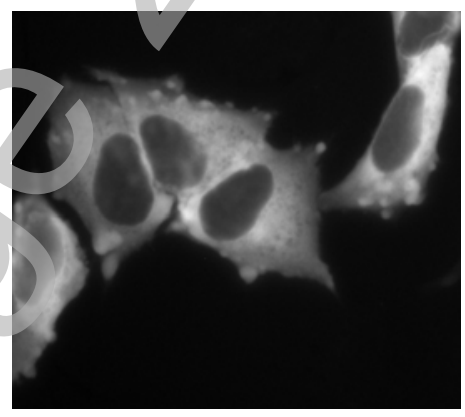

$180 \mathrm{~s}$

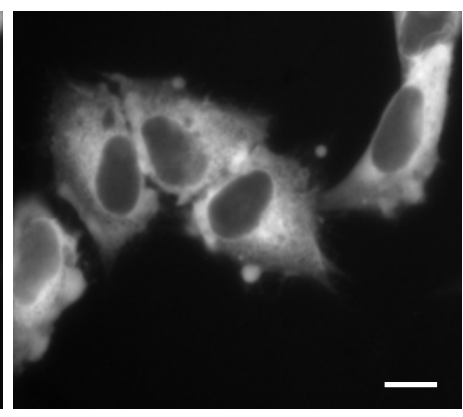

$300 \mathrm{~s}$ 


\section{Figure 4}

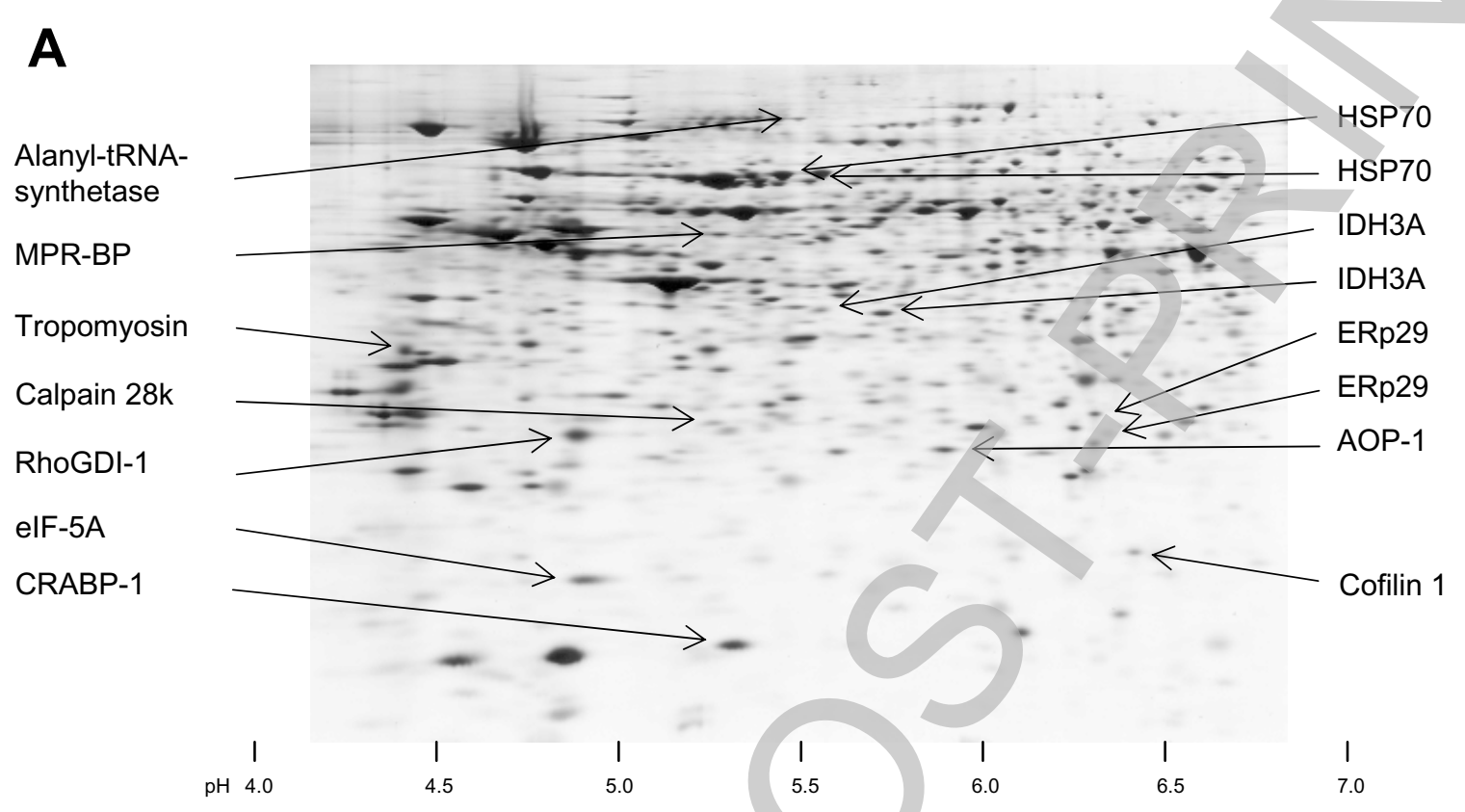

B

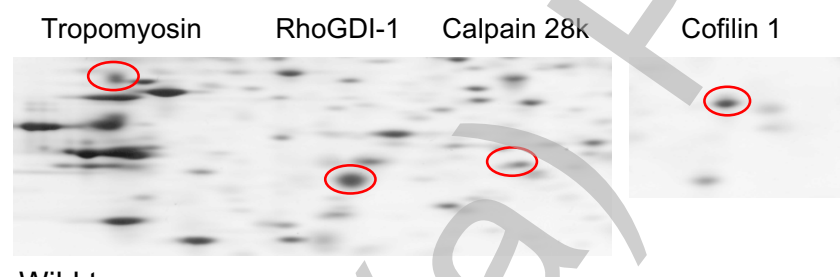

Wild type

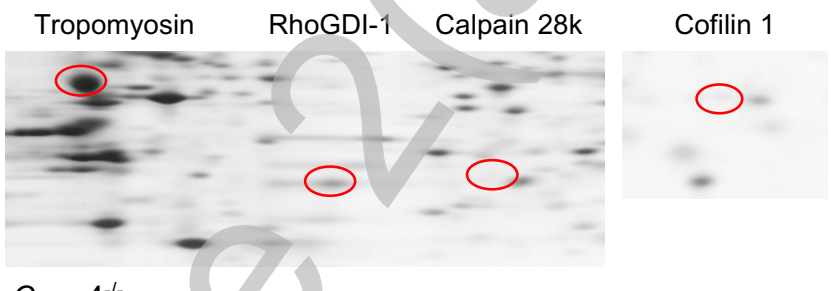

Capn4 ${ }^{-/}$

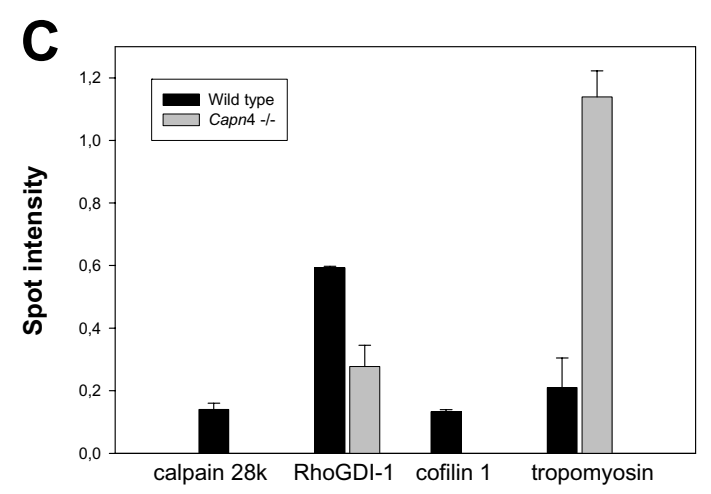


Figure 5

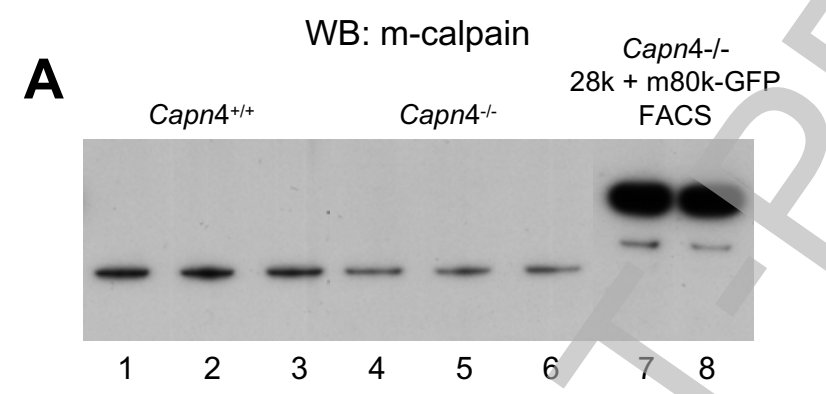

B WB: RhoGDl-1
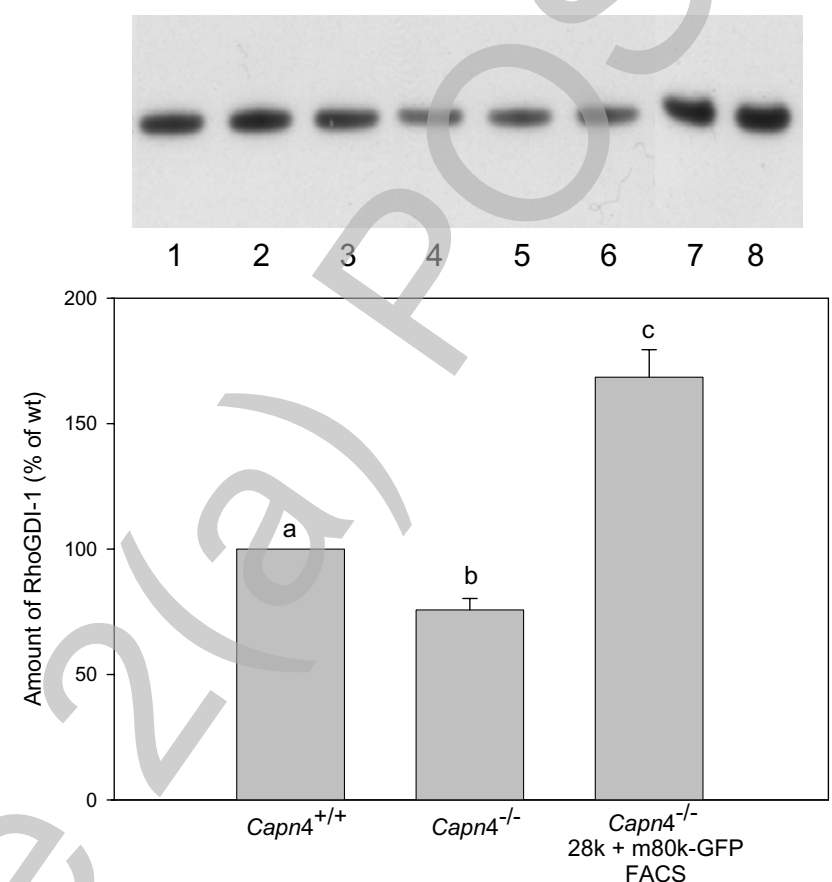

Licenced copy. Copying is not permitted, except with prior permission and as allowed by law. (C) 2007 The Authors Journal compilation (C) 2007 Biochemical Society 